\title{
Sebaceous carcinoma in situ as a diagnostic entity. Case report and review of the literature.
}

\author{
Leart Berdica ${ }^{1,2 *}$, Teona Bushati ${ }^{1,2}$, Alfred Aga ${ }^{3}$, Erisa Kola ${ }^{1}$, Rustem Celami ${ }^{5}$, Agron Dogjani ${ }^{6}$
}

Received: 04 May 2018; Accepted: 30 June 2018; Published online: 20 July 2018

DOI; https://doi.org/10.32391/ajtes.v2i2.11

\section{Abstract}

Background: The concept of carcinoma in situ was first introduced by Broders in 1932 [1] and has been accepted as a well-established notion and diagnostic category in many organs and systems. However, sebaceous carcinoma in situ (SCIS) has not yet been recognized as a concept and diagnostic entity in general pathology or dermatopathology. Such lesions have been commonly misinterpreted as either a benign neoplasm or sebaceous carcinoma. Tumors that do not necessarily arise in pre-existing sebaceous glands are usually invasive at the time of diagnosis, and like their ocular counterparts, can exhibit pagetoid intraepidermal spread. Cases of purely insitu extraocular sebaceous carcinoma are extremely rare and yet controversial until now.

Recognizing sebaceous carcinoma in situ as a valid concept and diagnostic entity that will certainly help to avoid misinterpretation and subsequently under or over treatment of such lesions.

In this article, we provide a case report presentation with histopathological examination and a critical review of the literature.

Keywords: SCIS, sebaceous adenoma, sebaceous carcinoma, extraocular sebaceous carcinoma in situ, histopathology diagnosis.

*Corresponding author: Leart Berdica

$\equiv$ Email: leartberdica@gmail.com

1,2 Department of Pathology “Mother Teresa” UHC, Tirana, Albania/Department of Pathology American Hospital, Tirana, Albania

${ }^{3}$ Head and Neck Surgeon, American Hospital, Tirana, Albania

${ }^{5}$ American Hospital, Tirana, Albania, FTMS, U. Elbasan, Albania

שUniversity Hospital of Trauma, Tirana, UMT, Albania 


\section{Introduction}

The benign "tumor-like" enlargements of the sebaceous glands have a histologic appearance which may not differ appreciably from that of the normal gland. There is no clear histologic distinction between the so-called adenoma of sebaceous gland and the hyperplastic and hypertrophic glands. The abnormality is chiefly one of increase in size, number and location of the glands with minor aberrations such as absence or atrophy of basal cells, variations in the tendency for the central cells to degenerate or absence of ducts.

Regarding the origin of sebaceous neoplasms, Kazakov et al. stated that "whereas in periorbital sebaceous lesions, it is accepted that sebaceous lesions arise from Meibomian glands and glands of Zeis, sebaceous glands elsewhere in the skin practically never appear to give rise to a sebaceous carcinoma". Sebaceous skin tumors can be sporadic or syndromic, as seen in association with MuirTorre syndrome (MTS).

Circumscribed lesions have been described according to their clinical characteristics:

(a) those occurring in old age, (b) congenital lesions or appearing during puberty and (c) lesions associated with other cutaneous and visceral pathologies forming the syndrome of Pringle's disease.

From the first classification of neoplasms with sebaceous differentiation proposed by Warren and Warvi in 1943 [2], to the one by Rulon and Helwig in 1974 [3], Lever in 1949 and 1989 [4, 5], Elder et al in 1997 and 2005 [6, 7], Prioleau and Santa Cruz in 1984 [8], Troy and Ackerman in 1984 [9] and Steffen and Ackerman 1994 [10], Mehregan and Hashimoto in 1991 and 1995 [11,12] and Burgdorf in 1990 [13], Farmer and Hood in 2000 [18], McKee in 1996 and 2012 [14,15], and Weedon in editions from 2002 to 2017 [19-22] The diagnostic entity of "sebaceous carcinoma in situ" was never mentioned in their classifications.

Classification of sebaceous neoplasms up to date has been made into three categories:

- Sebaceoma (a benign neoplasm with welldefined architecture and no atypia),

- Borderline sebaceous neoplasm (low-grade SC tumor with well-defined architecture and nuclear atypia)

- Sebaceous Carcinoma (a malignant tumor with invasive growth and evident nuclear atypia).

\section{Case presentation}

A 56-year-old male presented with a history of a rapidly-growing lesion in the lateral aspect of his nose. Upon examimation, the dermatologist noted another lesion in his mental region showing an elevated yellowish, exophytic nodule measuring $0.9 \mathrm{~cm}$ in greatest diameter. The surgeon decided to remove the mental lesion too (Figure 1).

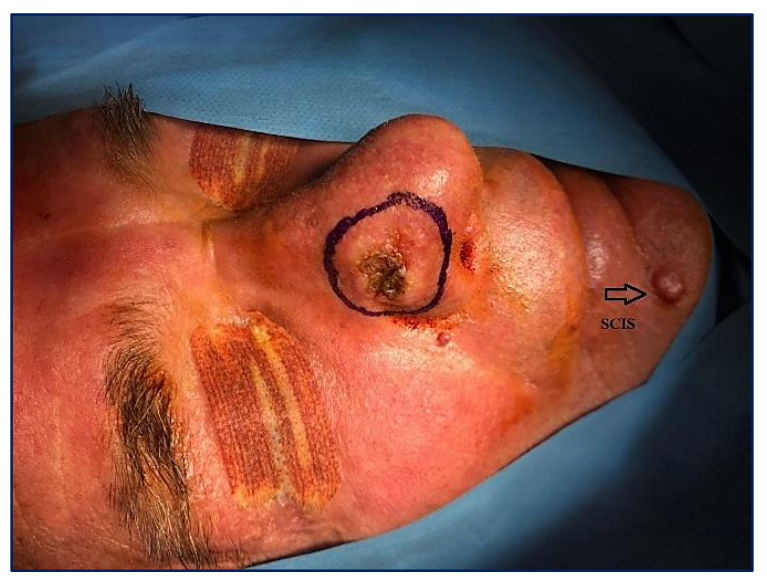

Figure 1. The marked lesion is the main complaint that brought the patient to the dermatologist. A second lesion is noted on the right aspect of the mental area, which according to the patient, is an old lesion that has been slowly growing over the past years. 


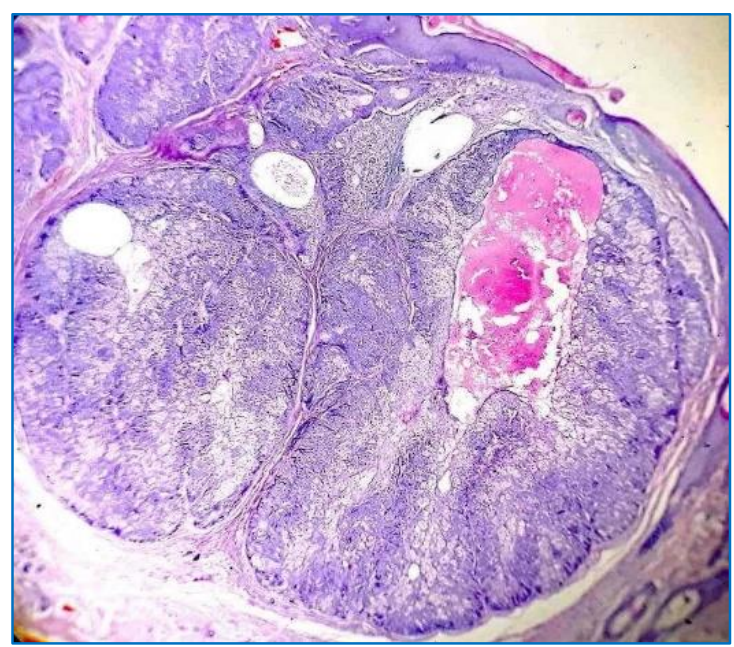

\section{Microscopic examination}

Figure 2. H\&E stain on low magnification reveals: Lobular pattern neoplasia in the deep dermis. The lobules are composed of sebaceous cells preserving the original structure of the sebaceous glands. It is noted a peripheral population of hyperchromatic cells in all the lobules. The lobules do not demonstrate any focus of disruption of the basal membrane. Surgical margins are free of disease.

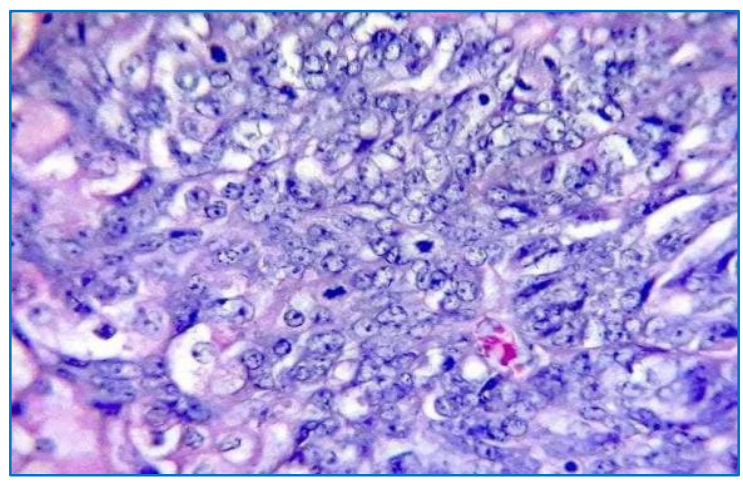

Figure 3. H\&E stain on high power reveals:

Increased population of atypical cells with high nuclear/cytoplasmic ratio, eosinophilic cytoplasm preserving the central granular clarification typical of sebaceous cells, enlargement of the nuclei and prominent nucleoli. The mitotic index is increased, as noted in the picture.

\section{Histopathological diagnosis:}

The first lesion was diagnosed as well-differentiated invasive squamous carcinoma, keratinized type. Lateral margins and depth are free of neoplasia. The final diagnosis of the second lesion as described in the figures 1, 2, 3 was:

Sebaceous carcinoma in situ. Lateral margins and depth are free of neoplasia.

\section{Discussion}

Like the definition for any other type of carcinoma in situ, the definition of SCIS would be a sebaceous neoplasm with these microscopic features:

1. Architectural findings such as: no invasive growth, population of neoplastic cells still confined in epithelium not extending the basal membrane (within surface epithelium, infundibular epithelium, sebaceous gland, sebaceous duct or follicular epithelium);

2. Cytological features consistent of malignancy such as: nuclear atypia, enlarged nuclei, hyperchromasia, increase of $\mathrm{N} / \mathrm{C}$ ratio, increase of mitotic activity and/or presence of necrosis.

These histopathologic findings fit the exact definition of carcinoma in situ, a malignant epithelial neoplasm confined in the epithelium of origin, which was introduced by Broders in 1932. According to some authors, SCIS has a number of different histopathologic manifestations. There are three histopathologic types: flat, nodular and cystic types.

Well- and moderately-differentiated SCIS were initially called sebaceous adenoma by some authors $[3,28]$ and has been called this way by many authors up to this day. However, in an article published in 1998, Nussen and Ackerman revised this concept and stated that the so-called 
sebaceous adenoma is not a benign neoplasm but a sebaceous carcinoma [29]. This notion was mentioned in the second edition of a book dedicated to neoplasms with sebaceous differentiation published in 2009 [26]. Although this notion has been accepted by some authors, it is not shared by many others in the field of dermatopathology. In an article published in 2010, Chen proposed a different view and asserted that the so-called sebaceous adenoma is really SCIS based on the abovementioned definition of SCIS [23].

Diversely, poorly-differentiated or high nuclear grade nodular/cystic SCIS is often misinterpreted as sebaceous carcinoma. For example, a study by Kazakov et al. with five cases of sebaceous neoplasms showing architectural findings of benignancy and cytologic features of malignancy stated that "the classification of such lesions as sebaceoma (with atypia) or sebaceous carcinoma remains unresolved" [32]. This opinion was in contrast to that of Resnik, who reviewed the slides of the five neoplasms [33]. In Resnik's opinion, 4 out of the 5 cases represented sebaceous carcinoma and one sebaceoma. Based on the architectural features of benignancy (well-defined borders of the lobules with no invasive growth) and cytological features of malignancy (presence of nuclear atypia, increased mitotic figures including atypical ones and necrosis), Kramer and Chen thought most, if not all, of the five sebaceous neoplasms presented by Kazakov et al. are in fact examples of sebaceous carcinoma in situ [24].

\section{Conclusions}

In summary, we can justify sebaceous carcinoma in situ as a valid concept and diagnostic entity. Additionally, this also explains why this neoplasm does not recur or metastasize after simple complete excision. Since it is merely an "in situ" lesion, simple complete surgical excision will result in a cure rate that is essentially $100 \%$. Thereby, surgery is the treatment of choice for these patients.

Accordingly, for the reasons mentioned above, the so-called sebaceous adenoma is neither an adenoma nor an invasive carcinoma, but rather sebaceous carcinoma in situ. The histopathological criteria for diagnosing such lesions are clear, accurate and comprehensible.

Recognizing sebaceous carcinoma in situ as a distinct entity must be considered in order to prevent diagnostic misinterpretation, consequently avoiding under or over treatment of these patients.

\section{References}

1. Broders AC. Carcinoma in situ contrasted with benign penetrating epithelium. JAMA. 1932;99(20):1670-1674. doi: 10.1001/jama.1932.02740720024007

2. Warren S, Warvi WN. Tumors of sebaceous glands. Am J Pathol. 1943;19(3):441-459. 3. Rulon DB, Helwig EB. Cutaneous sebaceous neoplasms. Cancer. 1974;33(1):82-102.

4. Lever WF. Histopathology of the Skin. Philadelphia, PA: Lippincott; 1949.

5. Lever WF, Schaumburg-Lever G. Histopathology of the Skin. 7th ed. Philadelphia, PA: Lippincott; 1989.

6. Elder D, Elenitsas R, Jaworsky C, Johnson B., Jr . Lever's Histopathology of the Skin. 8th ed. Philadelphia, PA: Lippincott-Raven; 1997.

7. Elder D, Elenitsas R, Johnson B, Jr, Murphy GF. Lever's Histopathology of the Skin. 9th ed. Philadelphia, PA: Lippincott-Raven; 2005. 8. Prioleau PG, Santa Cruz DJ. Sebaceous gland neoplasia. J Cutan Pathol. 1984 Oct;11(5):396-414. 
9. Troy JL, Ackerman AB. Sebaceoma. A distinctive benign neoplasm of adnexal epithelium differentiating toward sebaceous cells. Am J Dermatopathol. 1984 Feb;6(1):7-13.

10. Steffen C, Ackerman AB. Neoplasms with Sebaceous Differentiation: A Method by Pattern Analysis Ackerman's Histologic Diagnosis of Neoplastic Skin Diseases. Philadelphia, PA: Lea \& Febiger; 1994.

11. Mehregan AH, Hashimoto K. Pinkus Guide to Dermatohistopathology. 5th ed. East Norwalk, CT: Appleton \& Lange; 1991. Epidermal precancer, squamous cell carcinoma, and pseudocarcinoma; pp. 501-521.

12. Mehregan AH, Hashimoto K, Mehregan DA, Mehregan DR. Pinkus' Guide to Dermatopathology. 6th ed. Norwalk, CT: Appleton \& Lange; 1995. Intradermal epithelioma; pp. 643644.

13. Burgdorf WHC. Tumor of sebaceous gland differentiation. In: Farmer ER, Hood AF, editors. Pathology of the Skin. Norwalk, CT: Appleton \& Lange; 1990. p. 615.

14. McKee PH, Marsden RA. Pathology of the Skin: With Clinical Correlations.2nd ed. London, UK: Mosby-Wolfe; 1996.

15. Calonje E, Brenn T, McKee P, Lazar A. McKee's Pathology of the Skin. 4th ed. Philadelphia, PA: Elsevier Saunders; 2011. (expert consult) 16. Barnhill RL. Textbook of Dermatopathology. New York, NY: McGraw-Hill; 1998.

17. Maize JC, editor. Cutaneous

Pathology. Philadelphia, PA: Churchill Livingstone; 1998.

18. Steffen C. Neoplasms with sebaceous differentiation. In: Farmer ER, Hood AF, editors. Pathology of the Skin. 2nd ed. New York, NY: McGraw-Hill; 2000. pp. 1035-1058.
19. Weedon D. Weedon's Skin Pathology. 2nd ed. New York, NY: Churchill Livingstone; 2002. 20. Weedon D. Weedon's Skin Pathology. 3rd ed. New York, NY: Churchill Livingstone; 2009. 21. Patterson JW. Weedon's Skin Pathology. 4th ed. Philadelphia, PA: Elsevier; 2016.

22. Johnston RB. Weedon's Skin Pathology

Essentials. 2nd ed. Edinburgh: Elsevier; 2017. 23. Chen S. A different view: sebaceous adenoma is sebaceous carcinoma in situ. [Accessed February 1 , 2017];Dermatopathology: Practical \& Conceptual. 2010 16(2):16

24. Kramer JM, Chen S. Sebaceous carcinoma in situ. Am J Dermatopathol. 2010;32(8):854-855. 25. Kazakov DV, Kutzner H, Spagnolo DV, et al. What is extraocular cutaneous sebaceous carcinoma in situ? Am J Dermatopathol. 2010;32(8):857-858 26. Ackerman AB, Nussen-Lee $S$, Tan MA. Histopathologic Diagnosis of Neoplasms with Sebaceous Differentiation. Atlas and Text. 2nd ed. New York, NY: Ardor Scribendi; 2009.

27. Currie GP, Plaza JA, Harris GJ. Intraepithelial sebaceous carcinoma: a case report of an unusual occurrence. Am J Dermatopathol. 2014;36(8):673676.

28. Lever WF. Sebaceous adenoma; review of the literature and report of a case. Arch Derm Syphilol. 1948;57(1):102-111.

29. Nussen-Lee $S$, Ackerman AB. Sebaceous "adenoma" is sebaceous carcinoma. [Accessed February 1, 2017];

30. Ackerman AB, Nussen-Lee S. Neoplasms in all organs of Muir-Torre syndrome are carcinomas: sebaceous carcinomas and squamous-cell carcinomas (keratoacanthomas) in skin and adenocarcinomas, squamous-cell carcinomas, and transitional-cell carcinomas in internal organs. [Accessed February 1, 2017];Dermatopatholology: Practical \& Conceptual. 
31. Kacerovska D, Drlik L, Slezakova L, et al. Cutaneous sebaceous lesions in a patient with MUTYH-associated polyposis mimicking Muir-Torre syndrome. Am J Dermatopathol. 2016;38(12):915923.

32. Kazakov DV, Kutner H, Spagnolo DV, et al. Discordant architectural and cytologic features in cutaneous sebaceous neoplasms - a classification dilemma: report of 5 cases. Am J

Dermatopathol. 2009;31(1):31-36.

33. Resnik KS. The concepts of carcinoma in situ and carcinoma. Am J Dermatopathol. 2010;32(8):855856 